\title{
Research on Design and Implementation of Intelligent Warehouse Management System in Z Company
}

\author{
Jie Zhu ${ }^{1}$, Xianzhong $\mathbf{Q i}^{2}$, Ying Huang ${ }^{2}$ \\ ${ }^{1}$ Information Institute, Beijing Materials Institute, Beijing, China \\ ${ }^{2}$ Department of Logistics Engineering, Beijing Materials Institute, Beijing, China
}

Email address:

13522707099@126.com (Jie Zhu)

To cite this article:

Jie Zhu, Xianzhong Qi, Ying Huang. Research on Design and Implementation of Intelligent Warehouse Management System in Z Company. International Journal of Science and Qualitative Analysis. Vol. 2, No. 3, 2016, pp. 30-35. doi: 10.11648/j.ijsqa.20160203.12

Received: August 14, 2016; Accepted: November 14, 2016; Published: December 29, 2016

\begin{abstract}
This paper aims at the practical problems of warehouse in $Z$ enterprise, constructing the intelligent storage system, through the use of RFID technology, sensor technology, ZigBee technology to improve information transmission efficiency of the system, shortening the system response time. The paper solved the problem which the warehousing activities can't be real-time controlled in the drawbacks of the product information in the warehouse.
\end{abstract}

Keywords: Storage, System, Information, Efficiency

\section{Introduction}

At present, the enterprise information management warehouse still relatively backward [1], but the current warehouse operations and inventory control operations are very complex and diverse, relying on artificial memory and manual entry, not only time consuming, and error-prone to the enterprise zone to huge losses, and therefore needed a warehouse management system platform for the coordination of all aspects of the operation.

In order to further standardize warehouse management, information technology, urgent need to build an efficient warehouse management system that supplies out of storage convenient, fast, accurate, and design a suitable warehouse management system implementation in the library of materials out of storage and intelligent management, to improve economic efficiency and management level of the inevitable choice.

Therefore, RFID technology [2] and ZigBee technology [3] introduced warehouse management, warehousing information accurate, real-time acquisition, improve warehouse management level, so as to enhance the competitiveness of the supply chain.

\section{System Architecture}

The networking layer sensing device to read data from the underlying system and were processed through the networking middleware, uploaded to the server by the network database application. Application layer access network services through a complete data calls to the data layer, provides warehouse management of the management processes of data management, query, and security control applications analysis and data, and provides a unified data interface with other applications collaborative work.

\section{System Processes and Schematic}

The system is designed for the enterprise storage management practical problems, combined with a general warehouse management processes to networking technology as the support, to build a warehousing operations, inventory operations, a library job and job-based retrospective intelligent warehouse management system to the introduction of the Internet of things technology, [4] used in warehouse management jobs, warehouse management processes intelligent transformation process. [5] Overall flow chart is as follows:

The specific warehousing operations, inventory operations process, the library operations and traceability process are as follows. 


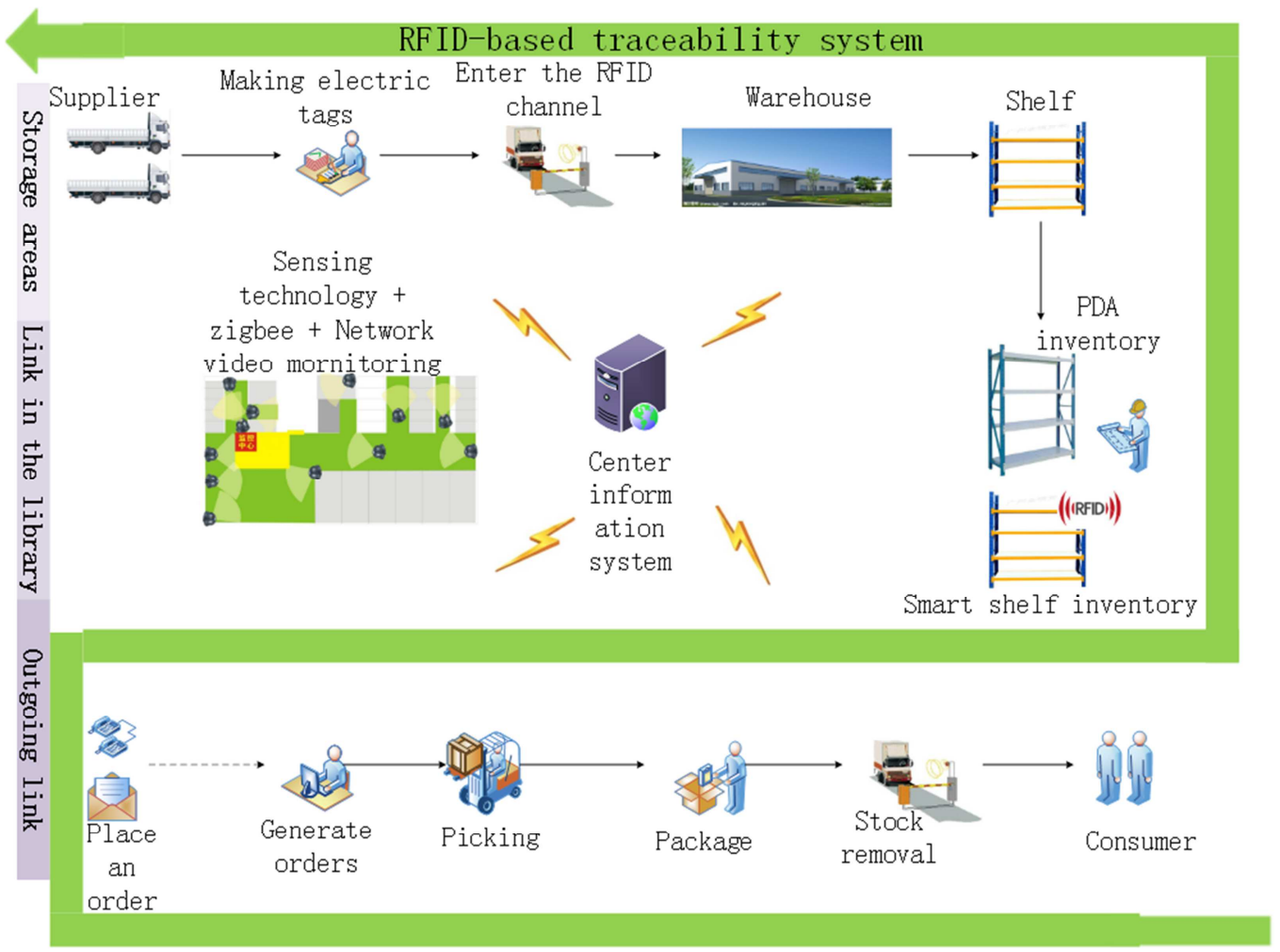

Fig. 1. Traceability system.

\subsection{Inbound Operation Process}

Enterprises for raw materials from upstream suppliers for transportation to the warehouse, paste made of anti metal RFID tags, [6] when carrying a stick good electronic label transport vehicles into the vehicle specified UHF RFID covered channel, placed in the label be collector reads the label information, through wireless or wired spread information system data, by the warehouse managers confirm storage, and complete the information collection operation storage. [7]

\subsection{Inventory Operation Process}

1, in view of the situation of high inventory turnover:

In need of inventory on hand inventory. By the system generated goods inventory list, through the technology of real time monitoring intelligent goods shelf system based on RFID technology, shows the raw material storage time, storage quantity and types, production date and other information, by smart shelf of automatic counting technology, real-time display of a related inventory information, and generate goods inventory of single check, and ultimately generate inventory file. The flow chart is as follows:

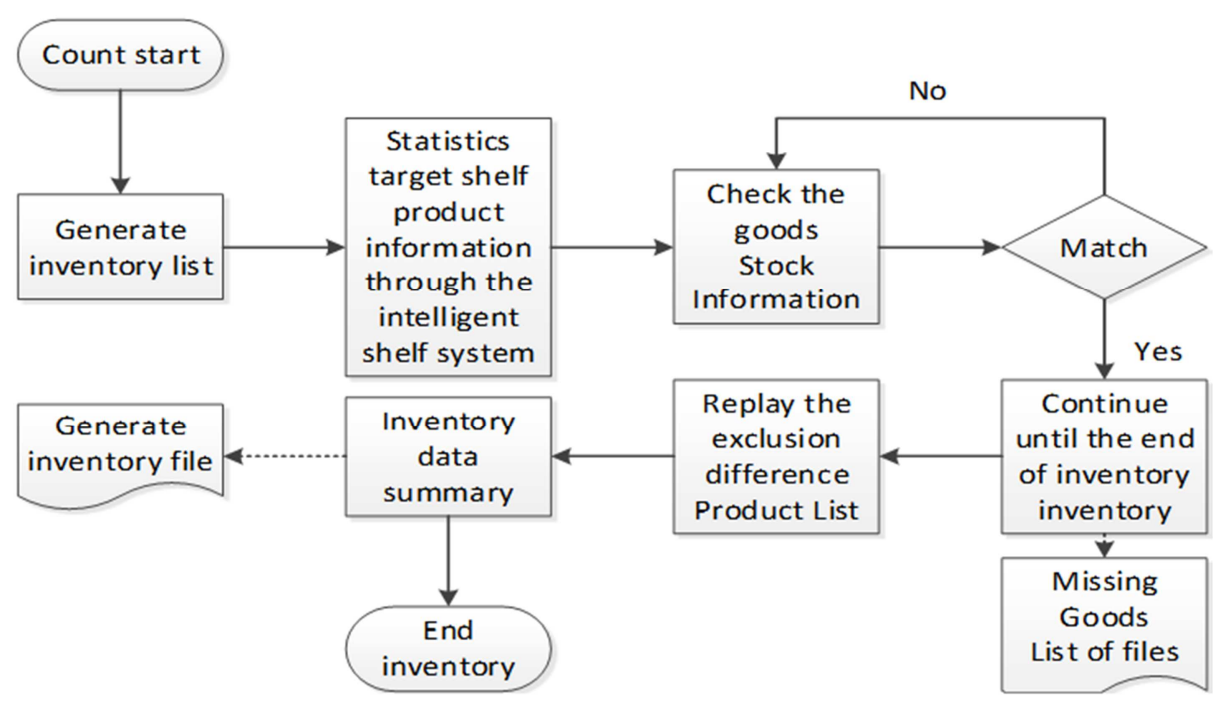

Fig. 2. Flow chart of the inventory. 
2 , in view of the situation of low inventory turnover:

For part of the inventory turnover rate low, due to the volume and the weight are larger, if because of inventory turnover and often have to change the location or placed on the smart shelves will cause great cost. This will the slower turnover placed in ordinary on the shelves, to economize on the use of smart shelves cost, in inventory using smart inventory car in the scope of work in on the shelf label were scanned data sent to the database to complete the inventory operations. [8]

\subsection{Out of the Library Operation Process}

Accept customer orders, processing of customer orders, in the RFID warehouse system of goods for query [9], selected in accordance with the requirements of the order of the goods generation picking orders, picking Dan Hao, warehouse area number, shelf number, location, etc., in front of the picking system through pre-set rules to generate visual graphical interface, prompt operation execution related information. The operator through the visual interface of the guide, to the goods storage areas were chosen, chosen for given commodities, by the terminal operation to center the sending database chosen successful information, after repeated selection, completion of customer orders goods picking, outbound packaging. A library of goods may not need to be packaged out of the library, but also possible to carry out a re packaging library. The flow chart is as follows:

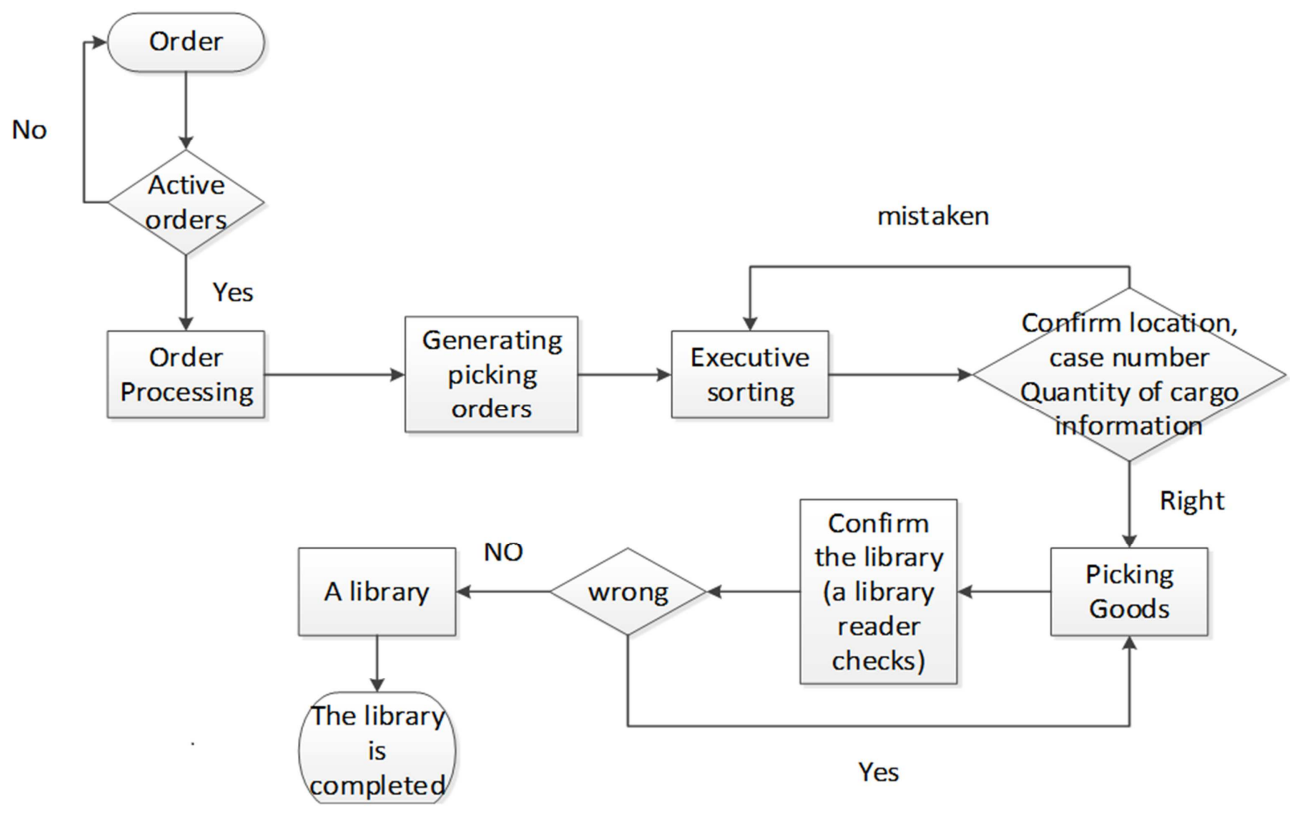

Fig. 3. Flow chart of library operations.

\subsection{Tracing Operation Process}

As part of the company's products are food, in order to improve the level of after-sales service, but also to provide protection for product safety, need to build traceability system. When the downstream customers find the products in question, through the handset, scanning attached in the anti metal tag, access to relevant information, and with superior sellers get in touch, reverse logistics; similarly, when major quality accidents can also through the same way gradually positioning of links, until you find the problem root [10].

\section{Key Technologies and Implementation}

\subsection{Based on Ultra High Frequency RFID Technology Out of Storage Intelligent Management System}

Based on ultra high frequency RFID technology out of storage intelligent management system, able to enter the ultra high frequency RFID coverage of the truck channel real-time intelligent control. When the truck carrying affixed with anti metal tag batch into the designated channel of RFID label has been activated and to the RFID reading and writing device sends a signal, collector reads the label information, through wireless or wired spread information system data, for part of the position are more characteristic, quantity is less, can use artificial handheld PDA scanning to supplement, by the warehouse managers confirm storage, and storage of information collection.

The entire RFID out of storage management system is mainly composed of RFID reader, the gate type channel type antenna and the host computer. By attaching the anti metal tag to the product, the intelligent management of the products in the warehouse and in the library is carried out.

Goods in storage before, in the packaging of goods in the form of hooks set up goods with an RFID tag to bind goods into warehouse in the process of RFID tags and RFID read write device between the RF signal to exchange information 
and reading and writing device and main control system through a network of information transmission, main control system for goods distribution a unique identity, in order to quickly locate the location of goods, but also to ensure that back the goods in the warehouse system. Throughout the goods in the warehouse in the process of circulation of goods information through the RFID tag and reader and the master control system for real-time transmission.

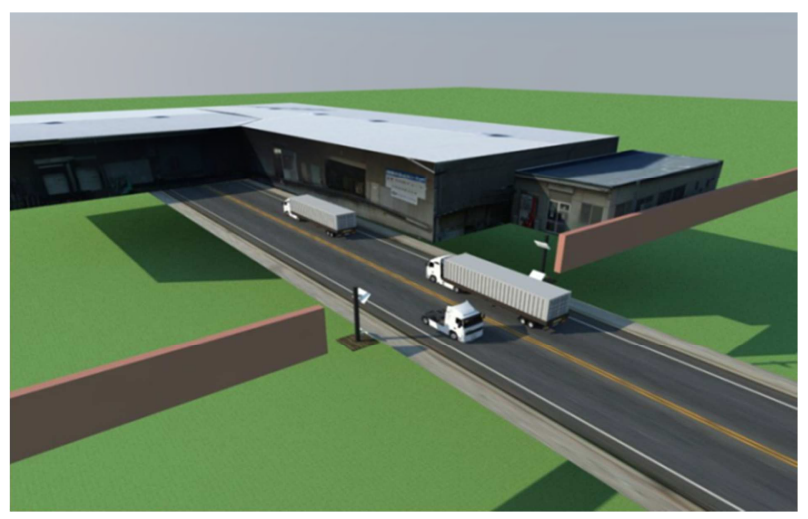

Fig. 4. Working schematic.

\subsection{Intelligent Inventory System}

Intelligent inventory system is mainly composed of ultra high frequency and high frequency RFID intelligent shelf inventory system. For depending on the flow rate, the high turnover rate of inventory and low turnover rate of inventory, the high turnover rate of inventory by RFID smart shelf inventory system; for low turnover rate of inventory using intelligent inventory system or artificial inventory.

Intelligent checking system, mainly used for important goods and materials of automation and transparent management, intelligent checking system mainly includes three kinds of physical inventory based on UHF RFID smart shelf system, based on high frequency RFID technology and ZigBee technology inventory management system, based on PDA Technology of hand counting method and the other is based on automatic checking vehicle automatic checking system.

(1) ultra high frequency RFID smart shelf inventory system

Using ultra high frequency radio frequency identification technology, using ultra-high frequency RFID reader, through the antenna multiplexer, each reader can take up to 256 antennas to achieve timing intelligent inventory. Can be scanned into the effective shelf area all RF tag, can be real-time monitoring, inventory time, can record real-time product storage shelves, shelf time, quantity, category, through the PC real-time display products in the library, inventory operations, do goods in automatic detection of prices of goods, without artificial one by one check and record.

(2) high frequency RFID intelligent rack counting system

Using high frequency RFID reader, through the deployment of the antenna on the shelf real time sensing in the rack material, to achieve intelligent inventory function. Intelligent sensor system is a perfect combination of ZigBee technology and sensing technology, using adsorption device, through flexible layout to under the condition of low cost, to the warehouse for effective monitoring. In particular, the use of ZIGBEE+RFID in the way, through the adsorption device, flexible layout in the shelf or the location of the warehouse.

In the warehouse can be arbitrary distribution, real time information of goods transport, and the realization of the server information exchange, provide strong support for the warehouse management system application layer. The specific application is shown below:

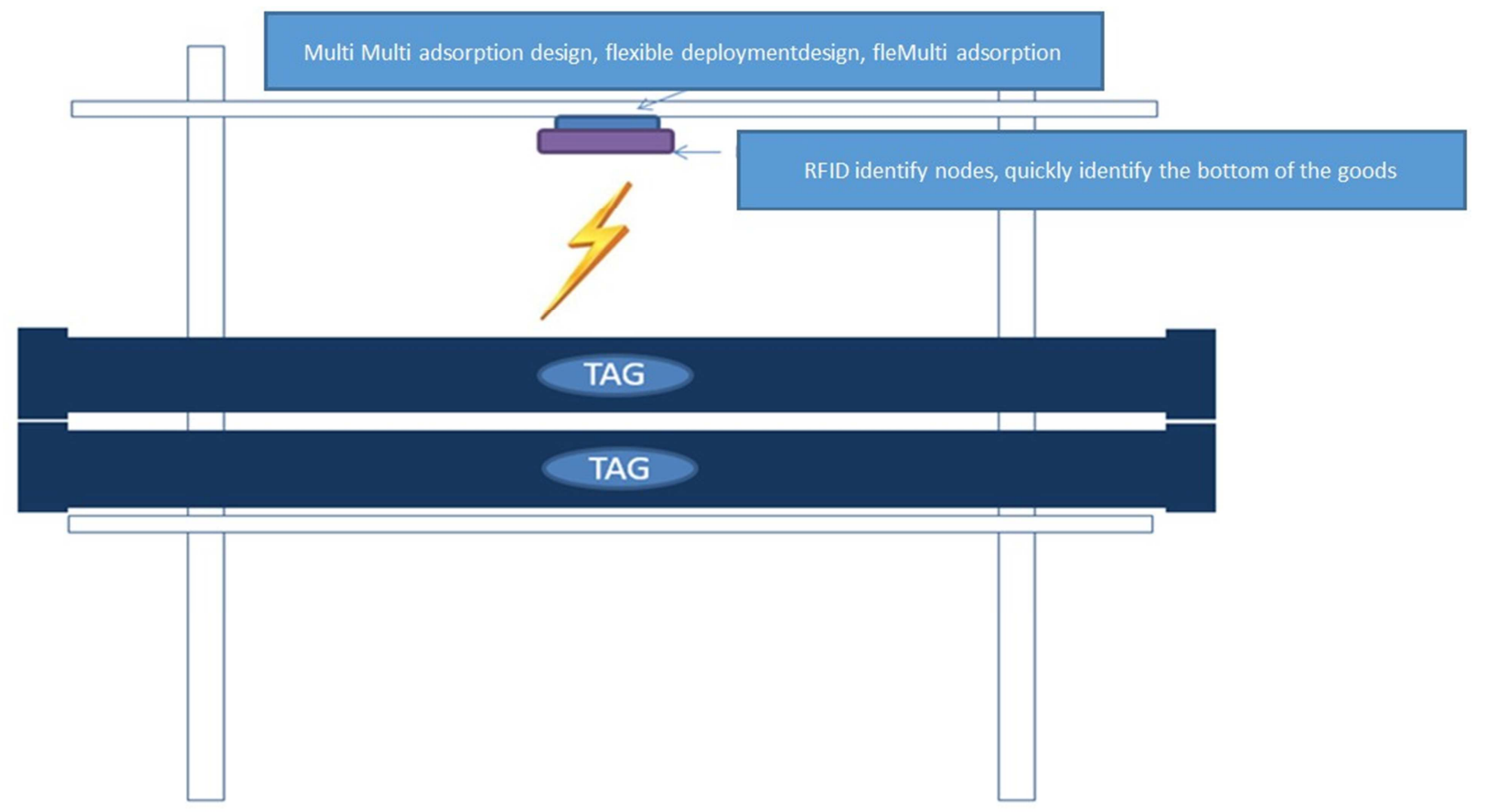

Fig. 5. Diagram of the Labeling Operation. 


\subsection{Warehouse Environment Monitoring System}

Intelligent storage monitoring system is the integration of sensor technology +Zigbee technology + network video surveillance equipment. It can obtain the information of the environment and the inventory information by multi technology, so as to realize the comprehensive monitoring of the warehouse.

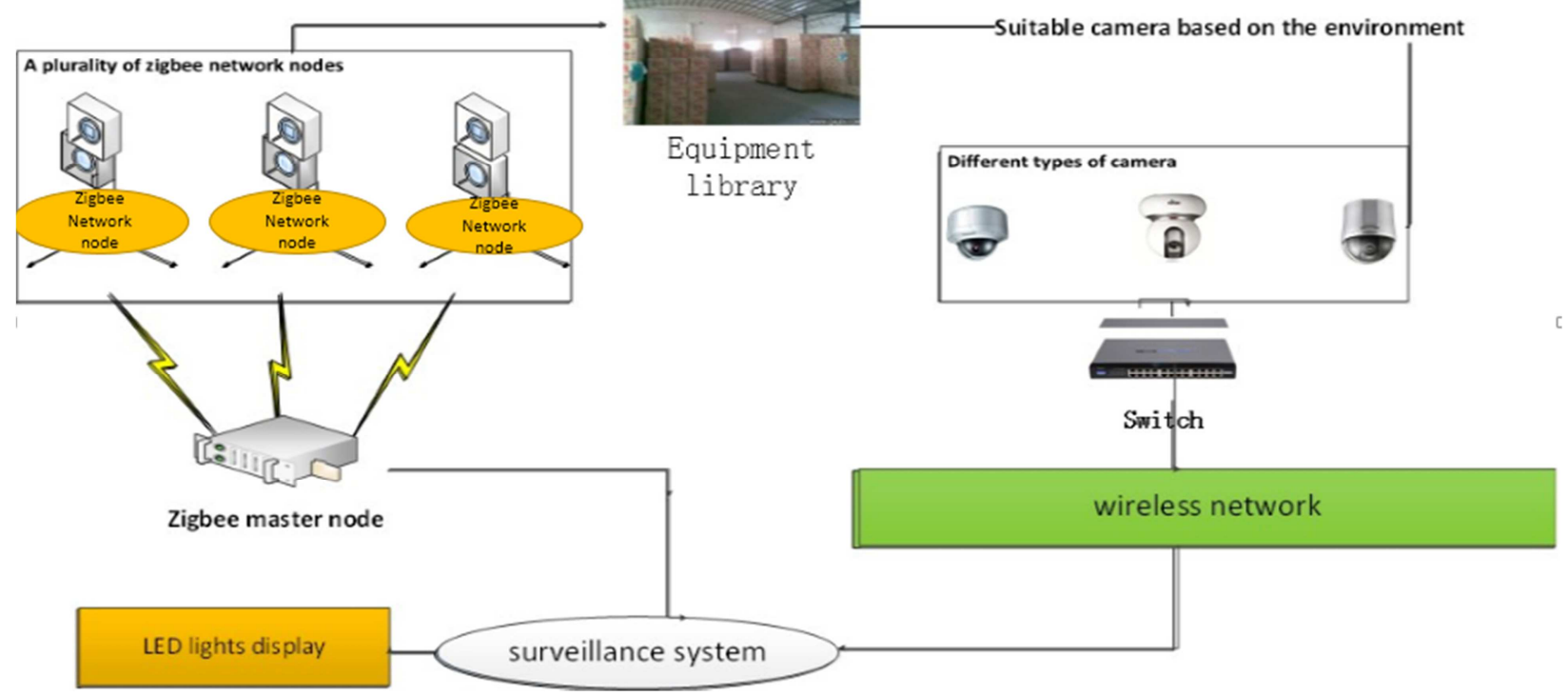

Fig. 6. Schematic diagram of warehouse monitoring.

Layer contains sensors and Zigbee combination, different types of camera, LED display equipment, according to the needs and the best results are arranged in the library, to achieve a comprehensive collection of data. The transmission layer comprises a Zigbee transmission module and a wireless network transmission protocol, which respectively undertake the transmission of the data collected by the sensor and the camera. Management is the collection to the data display and management interface, the data will display in the terminal software and LED lamp display. At the same time, by setting the security of the data line to remind Management Library of library environment adjustment, realize the integration of real management and monitoring. As illustrated:

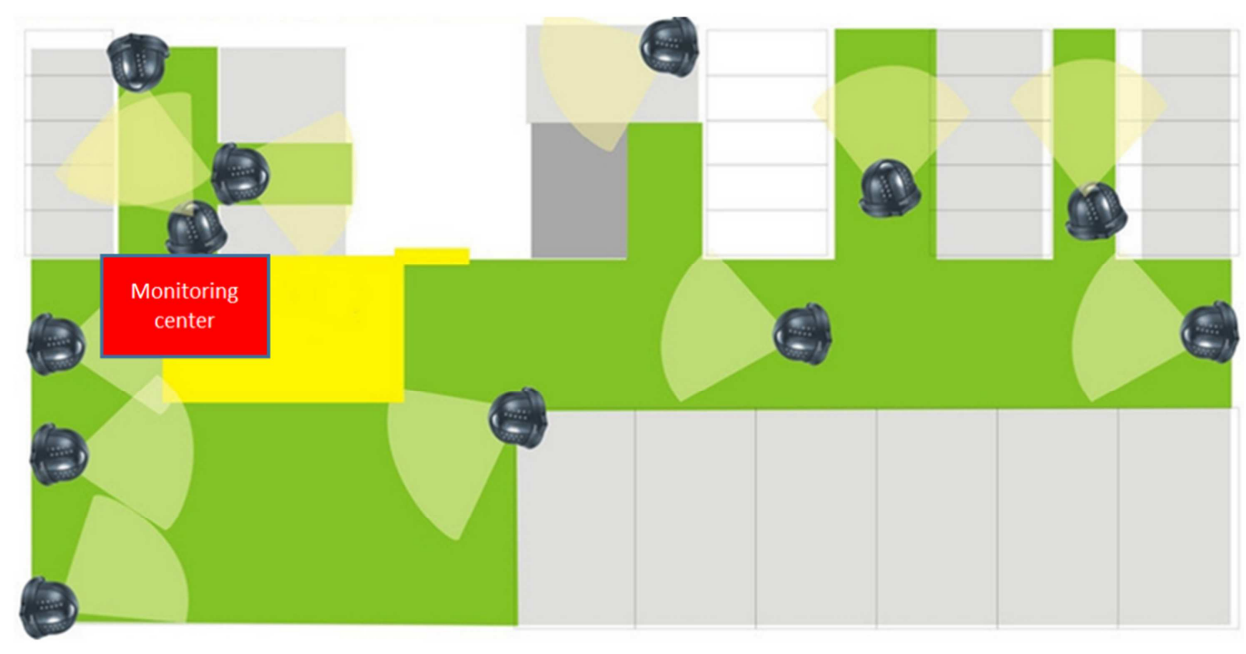

Fig. 7. Monitoring layout.

\subsection{Traceability System}

Product tracking system includes: product information label, product information read, product information association, product information recourse. In the product add anti metal RFID tags, product information in all phases of raw materials, production, warehouse, dealers and consumers are collected stored in the database of the manufacturer, once the enterprises need to query the information of any product at any stage, they can get the information through the information in the enterprise information in the database.

Each product in the library will be accompanied by anti 
metal RFID tags, the record label some production date, batch production, manufacturers and related production information, covering from the production of raw material suppliers, manufacturers, distributors to eventually a library of each work link, at the same time, a code for a unique identification, each product are promising appropriate identification. In quality and safety issues can be scanned by against the metal label, read electronic tag in stored products in various aspects of information, find the problems, discover the root of the problem, determine the party responsible for the problem and reduce the loss.

\section{Summary}

The design is based on the integration of design concepts, to avoid the existence of warehouse isolation, warehouse and management decision makers, customers, suppliers, the perfect convergence between the warehouse in the entire supply chain to play the biggest role, improve efficiency and reduce costs.

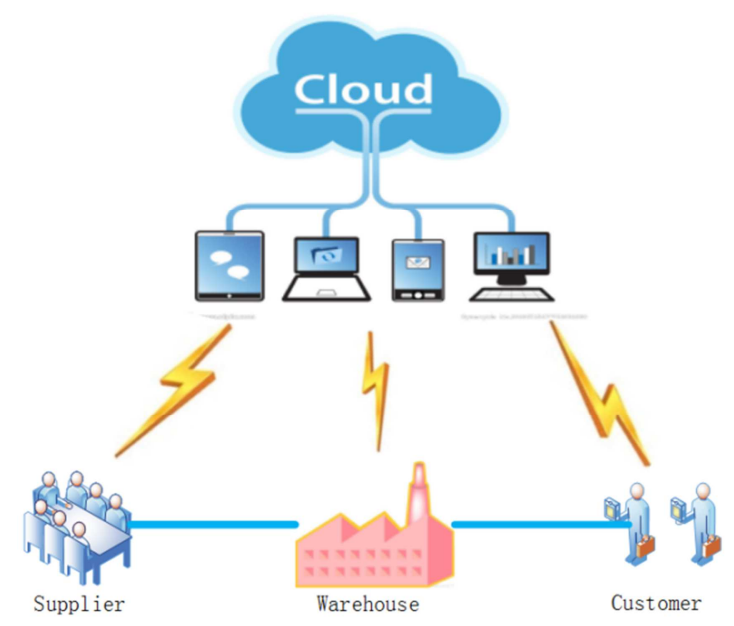

Fig. 8. Schematic of the supply chain.

\section{References}

[1] $\mathrm{Hu}$ Xiaoyan. Design of intelligent visual storage information management system [J]. logistics technology, 2014, 12, 25.

[2] Wan Juan. Wuhan University of Technology RFID based warehouse management information system research and design of [D]. Wuhan, 2013.

[3] $\mathrm{Xu}$ Zhipeng. Design and implementation of intelligent warehouse management system based on ZigBee technology [D]. Harbin, Harbin Engineering University, 2011

[4] Feng Liang. Research and system design of supply chain storage management based on [D]. RFID Ji'nan, Shandong University, 2010.

[5] Bo Yan, Ping Shi. Development of Traceability Platform for Aquatic Product Supply Chain Based on RFID and [D]. Transactions of the Chinese Society of Agricultural Engineering, 2013.

[6] Mark Harrision, Duncan McFarlane, Ajith Kumar Parlikad, Chien Yaw Wong. Information management in the product lifecycle - the role of networked RFID [C]. 2nd IEEE International Conference on Digital Object Identifier, Berlin, Germany, Jun. 2014: 507-12.

[7] Zhang Hao, Chen Yu. Real-time Logistics Tracking System Using RFID Technology and Wireless Communication [J]. Measurement and Control Technology, 2015, 24 (12): 68-70.

[8] He Diqiu, Gong Tianjun, Liao Ping. Part sorting system based on RFID technology [J]. Technology \& Electronics, 2015, (10): 6-8.

[9] Zhu Weiping, Sheng Huan Ye, Design and Implementation of Recon Fig. urable RFID Information Collection System [J]. Journal of Computer Applications and Software, 2014, 24 (10): 44-5.

[10] SHI Jia-liang, WANG Xiao-guo. Design of DVD Production Execution System (MES) Based on RFID Technology [J]. Journal of Computer Applications and Software, 2013, 24 (12): 208-9. 